\title{
Eggshell Qualities as Indicative of Eggshell Strength for Layer Selection
}

\section{-Author(s)}

\section{Kibala L'}

Rozempolska-Rucinska I"

Kasperek K"

Zieba G"

Lukaszewicz M"I

Centre for Nucleus Breeding MESSA Ltd., Mienia 100, 05-319 Ceglow, Poland

" Institute of Biological Bases of Animal Production, University of Life Sciences in Lublin, Akademicka 13, 20-950 Lublin, Poland

III Institute of Genetics and Animal Breeding, Polish Academy of Sciences, 05-552 Jastrzebiec, Postepu 36a, Poland

\section{Mail Address}

Corresponding author e-mail address Marek Lukaszewicz

Institute of Genetics and Animal Breeding, Polish Academy of Sciences, Postepu 36a, Jastrzebiec - 05-552 - Poland. Tel: $\quad(+48) 602758359$

Email: m.lukaszewicz@ighz.pl

\section{aKeywords}

Variance components, Selection criterion, Trait choice.

\section{ABSTRACT}

The study aimed at investigating which of four traits is the most representative of eggshell strength (destructive eggshell thickness measurement, eggshell weight, egg specific gravity, ultrasonic measurement of eggshell thickness) and could be used for selection purposes. To date, investigations focused mostly on pairwise (eggshell strength vs. another eggshell feature) analyses, resulting in two-, maybe three-trait, models when eggshell traits are considered. Since the covariance estimates are also model dependent, we collected five eggshell traits within one analysis, which better reflects what occurs in nature. The eggs were collected from 4571 Rhode Island White and 2426 Rhode Island Red hens. A multiple-trait animal model and the REML method were employed to compute variance components for calculation of heritabilities and genetic correlations between the traits. On average, the highest correlations were found between the destructive measurement and the other quality traits. It is concluded, however, that the ultrasonic eggshell thickness measurement, also with high genetic correlations with the other traits and leaving an egg intact for further handling, can suit best, as an indirect criterion, the selection for eggshell strength.

\section{INTRODUCTION}

Eggshell is a structure of major importance in layer breeding, influencing two economically vital aspects in commercial egg production - the eggshell protects the embryo, while enabling its development, and has an impact on the level of losses in the production of consumption or hatching eggs (Mertens et al., 2006).

Eggshell quality has long been subjected to genetic selection, and considerable improvement of eggshell quality has been reported (Hocking et al., 2003). Some main features of the eggshell are its strength expressed as the force needed to crack it, thickness, and weight. Before the emergence of non-destructive measurement devices (Kibala et al., 2015), destructive methods, leaving the egg unsuitable for further handling, were employed to evaluate eggshell quality. In order to avoid egg destruction, other traits genetically correlated with the eggshell strength, such as the ultrasonic measurement of eggshell thickness (ibid) and egg specific gravity (Rozempolska-Rucinska et al., 2011), were proposed as indicative of eggshell strength.

Any of the above egg traits may be employed as criterion for the selection for eggshell strength; however, only ultrasonic eggshell thickness measurement and egg specific gravity leaves the egg intact.

Although eggshell breaking strength is the ultimate measurement of eggshell strength, this study aimed at investigating which of the four other traits reflecting eggshell strength (destructive eggshell thickness 
measurement, eggshell weight, egg specific gravity, and ultrasonic measurement of eggshell thickness) is most representative of them all and could eventually be used for selection purposes.

\section{MATERIAL AND METHODS}

Since the performance data were obtained from the routine performance records of a commercial farm, Animal Care and Use Committee approval was not warranted.

Eggs of two layer populations, Rhode Island Red (RIR) and Rhode Island White (RIW), were collected on a single day of the $33^{\text {rd }}$ week of egg laying on the farm. Laying performance was evaluated based on an individual recording system. Altogether, eggs were collected from
4571 Rhode Island White (RIW) and 2426 Rhode Island Red (RIR) hens. The traits measured to evaluate eggshell quality were: egg specific gravity (ESG - calculated from the Archimedes' principle), eggshell strength (ES - measured with a device recording breaking strength with the accuracy of $0.01 \mathrm{~N}$ at a constant velocity of the measuring head shift equal to $50 \mathrm{~mm} / \mathrm{min}$ ), eggshell weight (ESW - measured on an electronic scale with accuracy of $0.1 \mathrm{~g}$ ), destructive eggshell thickness (DET - taken with an electronic micrometer at random points over the egg's equator towards the wide end, and ultrasonic eggshell thickness measurement (UET using a commercially available device for measuring the thickness of different materials).

The basic characteristics of the material are shown in Table 1.

Table 1 - Basic statistics of eggshell quality traits in Rhode Island Red (RIR) and Rhode Island White (RIW) hens

\begin{tabular}{llccccc}
\hline Breed & Variable & Number of hens & Mean & SD & Min & Max \\
\hline \multirow{4}{*}{ RIW } & Specific gravity $\left(\mathrm{g} / \mathrm{cm}^{3}\right)$ & 4468 & 1.072 & 0.008 & 1.020 & 1.100 \\
& Shell strength $(\mathrm{N})$ & 4431 & 40.2 & 9.0 & 10.0 & 71.5 \\
& Shell weight $(\mathrm{g})$ & 4462 & 7.4 & 0.7 & 4.9 & 9.9 \\
& Destructive shell thickness $(\mu \mathrm{m})$ & 4447 & 315 & 31 & 178 & 399 \\
& Ultrasonic shell thickness $(\mu \mathrm{m})$ & 4472 & 412 & 35 & 269 & 609 \\
\hline \multirow{4}{*}{ RIR } & Specific gravity $\left(\mathrm{g} / \mathrm{cm}^{3}\right)$ & 2407 & 1.071 & 0.009 & 1.020 & 1.100 \\
& Shell strength $(\mathrm{N})$ & 2369 & 40.0 & 10.2 & 8.5 \\
& Shell weight $(\mathrm{g})$ & 2400 & 7.3 & 0.6 & 4.9 & 9.7 \\
& Destructive shell thickness $(\mu \mathrm{m})$ & 2397 & 312 & 31 & 192 & 398 \\
& Ultrasonic shell thickness $(\mu \mathrm{m})$ & 2403 & 403 & 33 & 257 \\
\hline
\end{tabular}

Variance components required computing the genetic correlations among eggshell quality traits, and their heritabilities were estimated by the REML method using the following multiple-trait model:

$$
\mathrm{y}_{\mathrm{ij}}=\mu+\mathrm{YH}_{\mathrm{i}}+\mathrm{a}_{\mathrm{j}}+\mathrm{e}_{\mathrm{ij}}
$$

where:

$\mathrm{y}_{\mathrm{ij}}$ - vector of 5 observations on $j^{\text {th }}$ bird in $i^{\text {th }}$ contemporary group (ESG, ES, ESW, DET, UET);

$\mu$ - vector of 5 means of the traits;

$\mathrm{YH}_{\mathrm{i}}$ - vector of fixed solutions due to the combined effect of year of hatch and hatch no. within year of hatch;

$a_{i}$ - vector of random animal additive genetic solutions, pedigrees three generations deep;

$\mathrm{e}_{\mathrm{ij}}$ - vector of random residuals.

The computations were performed using the AIREMLF90 software of Misztal et al. (2002).

\section{RESULTS}

The additive genetic variability of the studied traits accounted for 16 to $22 \%$ of the total variability in the
RIW breed and for 26 to $42 \%$ in RIR (Table 2). In both breeds, ESW and UET presented the highest heritability estimates.

Table 2 - Heritabilities and their standard errors of eggshell strength quality traits in Rhode Island White (RIW) and Rhode Island Red (RIR) breeds

\begin{tabular}{lcccc}
\hline \multirow{2}{*}{ Breed Trait } & \multicolumn{2}{c}{ RIW } & \multicolumn{2}{c}{ RIR } \\
\cline { 2 - 5 } & $h^{2}$ & se & $h^{2}$ & se \\
\hline Specific gravity & 0.16 & 0.03 & 0.26 & 0.05 \\
Shell strength & 0.16 & 0.03 & 0.24 & 0.04 \\
Shell weight & 0.21 & 0.03 & 0.42 & 0.05 \\
Destructive shell thickness & 0.16 & 0.03 & 0.30 & 0.05 \\
Ultrasonic shell thickness & 0.22 & 0.03 & 0.37 & 0.05 \\
\hline
\end{tabular}

Table 3 presents the genetic correlations among the traits. The correlations proved to be moderate to very high, and of small standard errors. In both breeds, on average, the highest correlations were found between DET and the other quality traits. Somewhat lower genetic correlations, still with small standard errors, were recorded for UET. In addition, the genetic correlation between DET and UET was very high in both breeds, of 0.82 and 0.95 in RIW and RIR, respectively. 
Table 3 - Genetic correlations and their standard errors amongst the eggshell quality traits in Rhode Island White (beneath diagonal) and Rhode Island Red (above diagonal)

\begin{tabular}{lcccccccccc}
\hline & Specific gravity & \multicolumn{2}{c}{$\begin{array}{c}\text { Shell } \\
\text { strength }\end{array}$} & \multicolumn{2}{c}{$\begin{array}{c}\text { Shell } \\
\text { weight }\end{array}$} & \multicolumn{2}{c}{$\begin{array}{c}\text { Destructive } \\
\text { shell thickness }\end{array}$} & $\begin{array}{c}\text { Ultrasonic } \\
\text { shell thickness }\end{array}$ \\
\hline Specific gravity & & & 0.89 & 0.06 & 0.40 & 0.11 & 0.87 & 0.05 & 0.81 & 0.06 \\
Shell strength & 0.67 & 0.08 & & & 0.50 & 0.10 & 0.84 & 0.07 & 0.83 & 0.06 \\
Shell weight & 0.31 & 0.11 & 0.32 & 0.11 & & & 0.64 & 0.08 & 0.61 & 0.08 \\
Destructive shell thickness & 0.83 & 0.05 & 0.61 & 0.09 & 0.60 & 0.08 & & 0.95 & 0.03 \\
Ultrasonic shell thickness & 0.75 & 0.07 & 0.73 & 0.07 & 0.53 & 0.09 & 0.82 & 0.06 & \\
\hline
\end{tabular}

\section{DISCUSSION}

Eggshell quality, in its broad sense, largely depends on environmental factors, e.g. the age of the flock, moulting, nutrition, general stress, heat stress, diseases, production systems, and food supplements (Roberts, 2004). Nevertheless, the usefulness of a trait for genetic selection is determined by the genetic additive effects reflected by a sufficiently high heritability coefficient. The present analyses revealed that all traits were moderately or highly heritable, and had low heritability coefficient standard errors, while higher values were noted in the RIR breed. This difference may result from the different genetic structure of the breeds due to different selection pressures (maternal RIW vs. paternal RIR) for the traits included as selection criteria.

The range of genetic variability cannot be the sole determinant when deliberating the inclusion of a trait as selection criterion. The biological importance of a trait is also essential. In the current investigation, a total of five traits defining one broad indicator eggshell quality - was analyzed. This complex trait is often associated with eggshell strength, which defines the resistance of the eggshell to damage by an external force (Hamilton, 1982). Eggshell strength can be regarded as a reflection of an egg's mechanical and physical properties (Hammerle, 1969). The heritability of eggshell strength, reported by other authors, ranged between 0.10 and 0.35 (Dunn et al., 2005; Icken et al., 2006; Begli et al., 2010; Blanco et al., 2014). The discrepancy between these values is related to both the analyzed birds' genetic origin and the computation method. It was shown in the present study, however, that eggshell strength was highly correlated with other eggshell quality traits, with the highest correlations recorded between eggshell strength and the ultrasonic measurement of eggshell thickness in RIW and, in RIR, also with the destructive eggshell thickness. This result should not be surprising as eggshell thickness is an indirect trait for determination of its strength (Hamilton, 1982). A great problem in the case of eggshell strength is the destructiveness of the measurement and the impossibility of performing repeated measurements on the same egg. Hence, there may be differences among the results of crush tests applied on different areas of the eggshell (De Ketelaere, 2002). This is associated with the variable thickness of the eggshell, which in turn is highly correlated with eggshell crush strength (Yan et al., 2014; Kibala et al., 2015). Mechanical eggshell strength is determined by its thickness, which primarily reflects its structural properties (Bain, 2005) and it is highly responsible for the percentage of cracked eggs (Tyler and Geake, 1963). Thickness is one of the most important indirect measurements of eggshell strength; simultaneously, the magnitude of this trait is crucial in hatching eggs. Hatchability of eggs with thin shells is around 3-9\% lower (Bennett, 1992) than that of eggs with normal shell thickness, i.e., between 0.35 and $0.40 \mathrm{~mm}$ (Icken et al., 2006). Eggshell thickness is a trait of high genetic additive variability. Other authors reported higher heritability coefficient estimates than the present results, with values ranging from 0.19 to 0.57 (Icken et al., 2006; Begli et al., 2010).

Eggshell thickness can be measured via destructive analyses, which have been most frequently applied so far, but are inapplicable in commercial farms, or via non-destructive measurements, using, for example, the ultrasonic technology. It was shown in the present study that eggshell thickness, measured by either the destructive or non-destructive methods, is strongly correlated with the other traits, which confirms that eggshell thickness is indicative of the other traits of eggshell quality. Very high genetic correlations were recorded in both genetic strains between eggshell thickness and specific gravity (Table 3), which is another indicative trait used for eggshell strength assessment, as well as eggshell thickness.

Although the use of egg specific gravity for the genetic improvement of eggshell quality is sometimes controversial, the additive variability of egg specific gravity accounts for ca. $20 \%-45 \%$ of the total trait variability (Nirasawa et al., 1998; Ledur et al., 2003; Begli et al., 2010; Rozempolska-Rucińska et al., 2011), thereby making it a predictor candidate in effective 
selection for eggshell quality. The objections against the use of egg specific gravity as a trait that defines eggshell quality in a broad sense are mainly related to the fact that the reliability of this measurement largely depends on environmental factors, e.g., the duration of egg storage or the lag of measurement time (Voisey and Hamilton, 1977; Sloan et al., 2000). Despite these doubts, selection based on egg specific gravity has yielded positive results, as it reduced the number of eggs with thin shells by $3.4 \%$ in the study of McPhee et al. (1982).

Another indirect measure of eggshell strength is eggshell weight. This is, however, a destructive and labour-inefficient method, as it requires breaking the egg, washing the white out of the shell, as well as drying and weighing the shell. The genetic variability of this trait reported by other authors (Begli et al., 2010) was similar to that presented in this paper.

To sum up the analyses performed, it may be claimed that non-destructive ultrasonic shell thickness measurement can be used as a criterion in hen selection for eggshell strength. This trait shows a sufficient level of additive genetic variability and very strong genetic correlations with the other eggshell traits. Hence, only one indicator needs be used for defining the general eggshell strength quality.

\section{ACKNOWLEDGEMENTS}

The project was funded by the National Centre for Research and Development, Poland. Grant no. PBS2/ B8/8/2013.

\section{REFERENCES}

Bain MM. Recent advances in the assessment of eggshell quality and their future application. World's Poultry Science Journal 2005;61(2):268277.

Begli HE, Zerehdaran S, Hassani S, Abbasi MA, Ahmadi AK. Heritability, genetic and phenotypic correlations of egg quality traits in Iranian native fowl. British Poultry Science 2010;51(6):740-744

Bennett CD. The influence of shell thickness on hatchability in commercial broiler breeder flocks. The Journal of Applied Poultry Research 1992;1(1):61-65

Blanco AE, Icken W, Ould-Ali D, Cavero D, Schmutz M. Genetic parameters of egg quality traits on different pedigree layers with special focus on dynamic stiffness. Poultry Science 2014;93(10):2457-2463.

De Ketelaere B. Data analysis for the non-destructive quality assessment of agro-products using vibration measurements [thesis]. Leuven (BEL): Faculteit Landbouwkundige en Toegepaste Biologische Wetenschappen; 2002.

Dunn IC, Bain MM, Edmond A, Wilson PW, Joseph N, Solomon S, et al. Heritability and genetic correlation of measurements derived from acoustic resonance frequency analysis;a novel method of determining eggshell quality in domestic hens. British Poultry Science 2005;46(3):280-286.

Hamilton RMG. Methods and factors that affect the measurement of eggshell quality. Poultry Science 1982;61(10):2022-2039.

Hammerle JR. An engineering appraisal of egg shell strength evaluation techniques. Poultry Science 1969;48(5):1708-1717

Hocking PM, Bain M, Channing CE, Fleming R, Wilson S. Genetic variation for egg production, egg quality and bone strength in selected and traditional breeds of laying fowl. British Poultry Science 2003;44(3):365373

Icken W, Schmutz M, Preisinger R. Dynamic stiffness measurements with the" crack detector": a new method to improve egg shell strength. Lohman Information 2006;41:13-19.

Ledur MC, Liljedahl LE, McMillan I, Asselstine L, Fairfull RW. Genetic effects of aging on fitness and nonfitness traits in laying hens housed three per cage. Poultry Science 2003;82(8):1223-1234.

Kibala L, Rozempolska-Rucinska I, Kasperek K, Zieba G, Lukaszewicz M. Ultrasonic eggshell thickness measurement for selection of layers. Poultry Science 2015;94(10):2360-2363

McPhee $C P$, Burton HW, Fuelling DE. Selection for high specific gravity of eggs in a flock of Australorp hens. British Poultry Science 1982:23(3):215-223.

Mertens K, Bamelis F, Kemps B, Kamers B, Verhoelst E, De Ketelaere B, et al. Monitoring of eggshell breakage and eggshell strength in different production chains of consumption eggs. Poultry Science 2006;85(9):1670-1677

Misztal I, Tsuruta S, Strabel T, Auvray B, Druet T, Lee DH. BLUPF90 and related programs (BGF90) [cited 2017 Jul 18]. Proceedings of the 7th World Congress on Genetics Applied to Livestock Production; 2002; Montpellier, France. 2002. CD-ROM. Available from: http://nce.ads. uga.edu/wiki/lib/exe/fetch.php?media=28-07.pdf.

Nirasawa K, Takahashi H, Takeda H, Furukawa T, Takeda T, Nagamine, Y. Restricted maximum likelihood estimates of genetic parameters and genetic trends of chickens divergently selected for eggshell strength. Journal of Animal Breeding and Genetics 1998;115(1-6):375-381.

Roberts JR. Factors affecting egg internal quality and egg shell quality in laying hens. Journal of Poultry Science 2004;41(3):161-177.

Rozempolska-Rucińska I, Zięba G, Łukaszewicz M, Ciechońska M, Witkowski A, Ślaska B. Egg specific gravity in improvement of hatchability in laying hens. Journal of Animal and Feed Sciences 2011;20(1):84-92.

Sloan DR, Harms RH, Abdullah AG, Kuchinski KK. Variation in egg content density makes egg specific gravity a poor indicator of shell weight. Journal of Applied Animal Research 2000;18(2):121-128.

Tyler C, Geake FH. A study of various impact and crushing methods used for measuring shell strength. British Poultry Science 1963;4(1):49-61.

Voisey PW, Hamilton RMG. Sources of error in egg specific gravity measurements by the flotation method. Poultry Science $1977 ; 56(5): 1457-1462$.

Yan Y-Y, Sun C-J, Lian L, Zheng J-X, Xu G-Y, Yang N. Effect of uniformity of eggshell thickness on eggshell quality in chickens. Journal of Poultry Science 2014;51(3):338-342 